\title{
The effect of laminate lay-up on the flutter speed of composite wings
}

\author{
Guo, S.J. ${ }^{1}$ Bannerjee, J.R. ${ }^{2}$; Cheung, C.W. ${ }^{2}$ \\ ${ }^{1}$ Dept. of Aerospace, Automobile and Design Eng. University of Hertfordshire, Hatfield, UK \\ ${ }^{2}$ School of Engineering and Mathematical Sciences, City University, London, UK
}

\begin{abstract}
This paper presents an analytical study on optimization of a laminated composite wing structure for achieving a maximum flutter speed and a minimum weight without strength penalty. The investigation is carried out within the range of incompressible airflow and subsonic speed. In the first stage of the optimization, attention has been paid mainly to the effect on flutter speed of the bending, torsion and, more importantly, the bending-torsional coupling rigidity, which is usually associated with asymmetric laminate lay-up. The study has shown that the torsional rigidity plays a dominant role, while the coupling rigidity has also quite a significant effect on the flutter speed. In the second stage of the optimization, attention has been paid to the weight and laminate strength of the wing structure, which is affected by the variation in laminate lay-up in the first stage. Results from a thin-walled wing box made of laminated composite material show that up to 18 per cent increase in flutter speed and 13 per cent reduction in weight can be achieved without compromising the strength. The investigation has shown that a careful choice of initial lay-up and design variables leads to a desirable bending, torsional and coupling rigidities, with the provision of an efficient approach when achieving a maximum flutter speed with a minimum mass of a composite wing.
\end{abstract}

Keywords: LAMINATE LAY-UP; FLUTTER SPEED; $\underline{\text { COMPOSITE WINGS }}$

\section{INTRODUCTION}

In addition to the well-known high specific strength and stiffness, the use of composite materials in aircraft design offers many advantages to tackle the dynamic and aeroelastic problems, such as divergence, flutter and gust response. In some of the pioneering works [1-4], it was found that the warping restraint and elastic coupling have positive effect on the divergence speed of forward swept laminated composite wings. Investigation into the effect of elastic coupling on the flutter speed of composite wings has

In this paper laminates of both symmetric and asymmetric lay-ups with low and relatively high coupling rigidity have been examined for achieving an optimal design of a composite wing with a maximum flutter speed. In order to ensure an efficient way of also been carried out as evident from literature $[5,6]$. Later efforts have been made to optimise laminated composite wing structures to produce desirable aeroelastic effects [7-10]. It has been found that optimised asymmetric lay-up associated with relatively high coupling rigidity could be advantageous from an aeroelastic point of view. Symmetric lay-up associated with low coupling rigidity is normally undesirable for aeroelastic stability although it has often been employed in real life mainly due to the strength requirement and ease of manufacture.

achieving an optimal lay-up, two optimisation approaches have been investigated. In the first approach, the flutter speed was set in the objective function directly. In the second approach, optimisation was carried out to minimise an objective function containing the 
torsional and coupling rigidities rather than flutter speed. This was subsequently followed by a separate optimisation procedure to maximise the flutter speed. It has been noted that the optimal solution depends upon the initial lay-up, optimisation variables and the optimisation approach used. The solution for an optimised composite wing may not be unique although the final flutter speeds and lay-ups associated with different combination of bending, torsional and coupling rigidities often appear to be very close to the optimum. Because of the changes in fibre orientation, the rigidities and strength of the wing structure may be changed after the optimisation. An increase of torsional rigidity, which is generally in favour of flutter speed, is normally associated with a strength reduction of laminates. In order to regain the strength of the laminates reduced in the above stage, a second stage of optimisation was carried out. At this stage, it was chosen to optimise the cross sectional geometry of the original wing structure along its span instead of laminate thickness [10].

For illustrative purposes, a swept-back wing with a thin-walled box cross-section made of laminated carbon-epoxy material has been taken as the demonstration example in this paper. Accurate estimation of rigidity values of composite thin-walled box structures has been the subject of research for a number of investigators in recent years [11-15]. Based on an asymptotic analysis of two-dimensional shell theory, Berdichevsky et al. [14] developed the variational asymptotical theory to derive the governing equations of anisotropic thinwalled beams. Later Armanios and Badir [15] extended this theory to the free vibration analysis of anisotropic thin-walled beams. In the present work the method described in Ref.
[15] is used to determine the stiffness coefficients for thin-walled composite beams. The governing equations of motion in free vibration are rewritten in matrix form by using the dynamic stiffness method [16-17]. The Wittrick-Williams algorithm [18] is used to calculate the wing structural modes for higher accuracy and better computational efficiency. With regard to the unsteady aerodynamic loading calculations, as required for the flutter analysis, both the strip theory and lifting surface theory [19] have been used independently in order to check and validate the results. The well-known V-g method is finally used as a solution technique in the flutter analysis, which for the present problem is restricted to the lower range of the air speed.

\section{STRUCTURAL PROPERTIES AND MODAL ANALYSIS}

\subsection{Stiffness and strength of a composite box beam}

A swept-back composite wing of the planform as shown in Fig. 1 has been taken as an example in this paper. The laminated composite box section shown in Fig. 2 is basically the principal load carrying structure of the wing. Other parts forward of the front spar and behind the rear spar form part of the airfoil shape are assumed to contribute only to mass and inertia properties and also for the calculation of aerodynamic forces on the wing. The structural optimisation is therefore, limited to the box section of the wing. In order to compare the strength of different laminated lay-ups, classical lamination theory and the usual limit criterion [20] were employed.

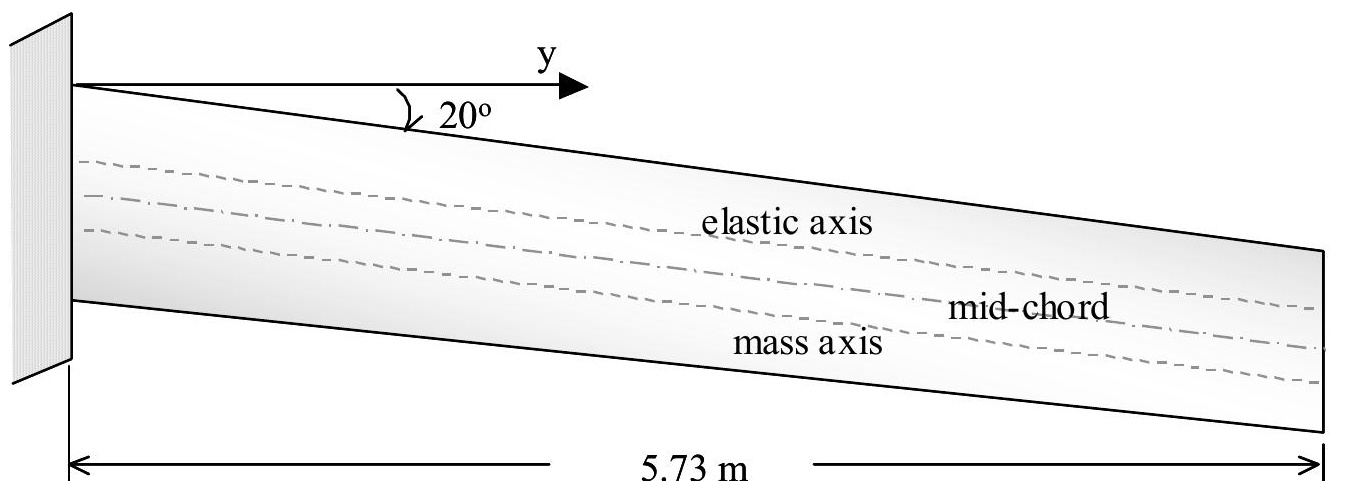


Figure 1. General layout and dimension of the swept-back composite wing

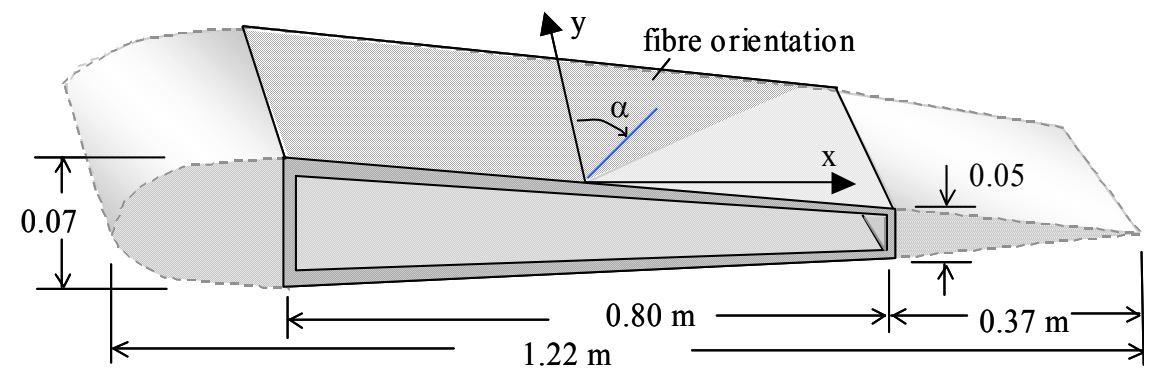

Figure 2. Cross-sectional details of the composite wing box

\subsection{Modal analysis using the dynamic stiffness matrix method}

The primary structure of the wing is idealised as a thin-walled laminated composite cantilever beam. The governing differential equations given by Lottati [6] amongst others are used as follows to represent the free vibration motion of the cantilever composite wing, but with the effect of shear deformation, rotatory inertia and warping ignored.

$$
\begin{aligned}
& E I \frac{\partial^{4} h}{\partial y^{4}}+K \frac{\partial^{3} \Psi}{\partial y^{3}}+m \frac{\partial^{2} h}{\partial^{2}}+m X_{\alpha} \frac{\partial^{2} \Psi}{\partial^{2}}=-L \\
& -G J \frac{\partial^{2} \Psi}{\partial y^{2}}-K \frac{\partial^{3} h}{\partial y^{3}}+m X_{\alpha} \frac{\partial^{2} h}{\partial^{2}}+I_{\alpha} \frac{\partial^{2} \Psi}{\partial^{2}}=M
\end{aligned}
$$

where $h$ and $\Psi$ are transverse displacement and rotation of the wing; $m, I_{\alpha}$ and $X_{\alpha}$ are mass, polar mass moment of inertia per unit length and distance between mass and geometric elastic axes of the wing crosssection, respectively.

The differential equations for each of the beam elements representing the wing are then rewritten in matrix form by implementing the dynamic stiffness matrix method [17]. The Wittrick and Williams algorithm [18] is subsequently used to calculate the natural frequencies and mode shapes of the composite cantilever wing structure represented by the assembly of the beam elements along the wingspan.

\section{FLUTTER ANALYSIS AND OPTIMISATION}

\subsection{Flutter analysis using the determinant and $V$-g methods}

Using the normal mode method, the flutter equation for an oscillating wing in the range of incompressible airflow and subsonic speed can be written in generalised coordinates as:

$$
\left[\left[K_{D}(\omega)\right]-\frac{\rho V^{2}}{2}[Q A]_{R}+i \omega \cdot[D]+i \frac{\rho V^{2}}{2}[Q A]_{I}\right]\{q\}=0
$$

where $\left[K_{D}(\omega)\right]$ is a frequency dependent dynamic stiffness matrix and $[D]$ the damping matrix of the structure; $[Q A]_{R}$ and $[Q A]_{I}$ are the real and imaginary parts of the generalised 
aerodynamic matrix as a function of the reduced frequency parameter $\mathrm{k}=\omega \mathrm{b} / \mathrm{V}$, respectively.

For computational efficiency, the V-g method is used; and for accuracy, the determinant method is also used as an alternative way to calculate the flutter speed and frequency. In order to implement the V-g method, the above flutter equation needs to be rewritten in a suitable form so as to present a standard complex eigenvalue problem. This procedure requires the unknown frequency $\omega$ to be expressed explicitly in the dynamic stiffness matrix. It was thus necessary to express the dynamic stiffness matrix $\left[K_{D}(\omega)\right]$ in the form of Taylor's series expansion with the stiffness and mass matrices being separated as follows.

$$
\left[K_{D}(\omega)\right]=[K]_{0}-\omega^{2}[M]_{0}-\omega^{4}[M]_{1}-\ldots
$$

It is clear from equation (4) that when high order terms above $\omega^{2}$ are ignored, $[K]_{0}$ and $[M]_{0}$ reduce to finite element stiffness and mass matrices as a degenerate (approximate) case of the dynamic stiffness matrix $\left[K_{D}(\omega)\right]$. Having performed the exact modal analysis based on $\left[K_{D}(\omega)\right]$, the approximation $\left[K_{D}\left(\omega_{j}\right)\right]=[K]_{0} \quad-\omega_{j}^{2}[M]_{0}$ is now introduced into the flutter equation to give

$$
\left[[K]_{0}-\frac{\rho V^{2}}{2}\left([Q A]_{R}-i[Q A]_{I}\right)+i \omega[D]-\omega^{2}[M]_{0}\right]\{q\}=0
$$

\subsection{Unconstrained optimisation for maximum flutter speed (stage-1)}

At this stage of optimisation, effort is primarily focused on achieving a maximum flutter speed by taking the advantage of tailor ability of fibre reinforced laminates over isotropic materials. Since the wing weight will not be affected by fibre orientation, an unconstrained optimisation problem is therefore formulated and expressed as follows:

minimise $f_{v}(\alpha)$ within $\left\{\alpha_{l}\right\} \leq\{\alpha\} \leq\left\{\alpha_{u}\right\}$ where $f_{v}(\alpha)$ is the objective function and $\alpha$ represents the fibre orientation as design variable with $\left\{\alpha_{l}\right\}$ and $\left\{\alpha_{u}\right\}$ being the lower and upper bounds.

In solving the above optimisation problem, the Davidson-Fletcher-Powell (DFP) variable metric method [21] is used as the optimiser whereas the Golden Section method [22] based on polynomial interpolation is used for the one-dimensional search. The following non-dimensional objective function is formulated to minimise $f_{v}(\alpha)$, i.e. to maximise the flutter speed:

$$
f_{v}(\alpha)=\left(1-\frac{V_{f}(\alpha)-V_{f}\left(\alpha_{0}\right)}{V_{f}\left(\alpha_{0}\right)}\right)^{2}
$$

where $V_{f}\left(\alpha_{0}\right)$ and $V_{f}(\alpha)$ represent the flutter speeds of the wing box structure with the laminate fibre orientation $\alpha_{0}$ in the initial design and optimised $\alpha$, respectively.

A large amount of computing time will be inevitably required in this approach because flutter speed need to be calculated repeatedly in the whole optimisation procedure. An alternative and more efficient approach would be to involve the flutter analysis at a new favourable lay-up rather than from the initial lay-up. From the classical theory of aeroelasticity it is generally known that the torsional rigidity of a wing has relatively larger effect on aeroelastic behaviour than its bending rigidity. In addition, it has been found from previous research [9] that in the particular context of a composite wing the bending-torsion coupling rigidity $K$ also has significant effect on flutter characteristics. Therefore an objective function involving the torsional $(G J)$ and coupling $(K)$ rigidities, is formulated as follows (this was used to achieve the most favourable lay-up before performing the flutter calculation):

$$
f_{v}(\alpha)=\frac{G J\left(\alpha_{0}\right)+K\left(\alpha_{0}\right)}{G J(\alpha)+K(\alpha)}
$$

A minimum value of the above objective function may not necessarily correspond to a design that gives the maximum flutter speed. 
However the optimal solution obtained by using equation (8) will no-doubt provide a favourable lay-up that will increase the flutter speed. Starting from such a new lay-up, it is expected that computing time can be significantly reduced in the subsequent optimisation when employing equation (7) and thus the overall aeroelastic tailoring would be more efficient.

\subsection{Constrained optimisation for minimum strength reduction (stage-2)}

As a result of the above stage- 1 procedure, the optimised wing box normally has a larger torsional rigidity associated with the change in fibre orientations. This may cause an increase of maximum stress and failure index in the laminates subjected to a force and hence a reduction in strength. To this end the maximum stress theory has been applied to the laminate strength analysis. In order to minimise the strength reduction, a second stage of optimisation has been carried out by taking the cross sectional dimensions of the wing box along its span as design variables. The flutter speed was taken as a constraint condition so as to maintain the maximum flutter speed achieved in stage-1. The total weight of the wing was also considered in the optimisation. Instead of creating an additional constraint condition, the weight was combined together with the stress to create an objective function $f_{s}(c)$ as presented below. This second stage optimisation was carried out by solving the following constrained optimisation problem:

$\operatorname{minimize} f_{S}(c)=\frac{1}{2}\left(\left(R_{S}(c)-1\right)^{3}+R_{W}(c)^{2}\right)$

subject to $\quad G(c)=\frac{V_{f}(c)-V_{\max }}{V_{\max }} \geq 0$

within $\left\{c_{l}\right\} \leq\{c\} \geq\left\{c_{u}\right\}$

where $R_{s}(c)=\sigma_{1 t}(c) / \sigma_{0}$ represents a ratio of the maximum tensile stress in fibre direction in the optimised laminates against that in the initial design of the wing box; $R_{w}(c)=W(c) / W_{0}$ represents a ratio of weight of the optimised wing box against the initial design; $V_{\max }$ and
$V_{f}(c)$ represent the maximum flutter speed achieved in stage 1 and the optimised flutter speed in stage 2 respectively; $\{c\}$ represents the cross-section dimensions of the wing box along its span taken as design variables with lower and upper bounds, $\left\{c_{l}\right\}$ and $\left\{c_{u}\right\}$ respectively.

In stage 2, the constrained optimization was converted into a sequence of unconstrained optimisation problems by using the penalty function method. The BroydonFletcher-Goldfarb-Shanno (BFGS) method was used as optimizer and the Golden Section method was used for one-dimensional search [22].

\section{EXAMPLES AND DISCUSSION}

\subsection{Initial laminate lay-up}

In the composite wing example shown in Fig.1, the uniform thin-walled box beam of the cross-section as shown in Fig. 2 forms the primary wing structure. The left and right sides of the box play the role of the front and rear spars while the top and bottom sides represent the wing skins. In the initial lay-up, each side of the box beam is made up of symmetric laminates consisting of eight plies with stacking sequence presented in Table 1 (see Fig. 2). This choice was influenced by the fact that such lay-ups provide a reasonably high bending and torsional rigidity and also good combination of laminate strength in all directions for the wing. When taking the fibre orientations as design variables in this case, the total number of independent design variables for the wing box is 16 . Although the laminate on each side is limited to symmetry, the lay-up on different sides could be different after the optimisation and may result in asymmetric lay-up for the whole wing box section associated with non-zero coupling rigidity. The computed bending, torsional, coupling rigidities and flutter speeds using strip and lifting-surface (L-S) theory respectively, are given in Table 1.

\subsection{Aeroelastic optimisation by fibre tailoring (stage 1)}




\subsubsection{Direct aeroelastic optimisation approach}

Symmetric lay-up (case 1). In the first attempt at optimisation, fibre orientations on each side of the box section were changed together and limited to symmetric lay-up. Hence there were only four design variables involved in the optimisation. In this first approach of optimisation, the objective function expressed in equation (7) was employed directly to search for the maximum flutter speed. As the result, the bending-torsion coupling rigidity remained zero like the initial lay-up and an optimal lay-up with maximum flutter speed at $\alpha=45$ was obtained as shown in Table 1 (see results for case 1).

Asymmetric lay-up (case 2). It was expected that higher flutter speed could be achieved if the lay-up was not limited to symmetric case. Therefore, in the second attempt the optimisation was restarted from the initial layup using equation (7). Without symmetric layup limitation, four fibre orientations on each side of the box section involving a total of 16 design variables were now used in the optimisation. As expected, more computing time was consumed to achieve the final solution. As shown in Table 1 (see results for case 2), the results indicate a different lay-up from that of the case 1 and give a higher flutter speed. It has been noted that little change occurs in the laminates comprising the front and rear spars because the flutter is not sensitive to their lay-up in this case.

Asymmetric lay-up (case 3). From the previous case 2 results, it has been realised that the optimisation efficiency may be improved by selecting only those design variables that have significant effect on flutter speed. In this case therefore, only the fibre orientations in the top and bottom skins were taken as design variables in the optimisation. With reduced computing time an optimal lay-up was obtained and shown in the case 3 results of Table 1. These results give an alternative design solution with the lay-up in the front and rear spars remaining the same as initial design but the skin lay-up being different from that of case 2. It is also interesting to note that both the torsional and the coupling rigidities and also the achieved flutter speed are slightly higher than those of case 2 .

\subsubsection{Indirect aeroelastic optimisation approach}

Rigidity optimisation (case 4.1). From the above results, it has been noticed that a combination of relatively large torsional and coupling rigidities may result in a high flutter speed. For further investigation, an alternative approach was attempted with the expectation of a more efficient optimisation and a better solution. Starting from the initial lay-up, the rigidity-based objective function expressed in equation (8) was employed first. There were 16 design variables involved in the optimisation without limiting the case to a symmetric lay-up. A stacking sequence with the maximum sum of torsional and coupling rigidities for the wing box was obtained and listed in Table 1 (see results for case 4.1). Since the optimisation does not involve flutter calculation yet, the computing time was significantly reduced. For the same reason however, the maximum flutter speed is yet to be achieved although over 10 percent increase of flutter speed against the initial design has so far been obtained. Because all the four sides of the wing box section contribute to the torsional and coupling rigidities, all design variables have been changed in this case. Comparing these results with those of case $2 \& 3$, it is clear that a larger coupling rigidity or sum of torsional and coupling rigidities does not necessarily result in a higher flutter speed. The maximum flutter speed must be associated with a more rational combination of the torsional and coupling rigidities than that presented in equation (8). 
Table 1. Optimisation Results of the Composite Wing Box

\begin{tabular}{|c|c|c|c|c|}
\hline Case & Lay-up(degree) & $\begin{array}{c}\text { Rigidities } \\
\left(\mathrm{MN} . \mathrm{m}^{2}\right)\end{array}$ & $\begin{array}{l}\text { Flutter speed } \\
\text { Frequency } \omega_{\mathrm{f}} \\
\text { (strip theory) }\end{array}$ & $\begin{array}{l}(\mathrm{m} / \mathrm{s}) \\
(\mathrm{rad} / \mathrm{s}) \\
(\mathrm{L}-\mathrm{S} \text { theory) }\end{array}$ \\
\hline $\begin{array}{l}\text { Initial } \\
\text { lay-up }\end{array}$ & $\begin{array}{ll}\text { top skin } & {[30 /-30 / 30 /-30]_{\mathrm{s}}} \\
\text { bottom skin }[-30 / 30 /-30 / 30]_{\mathrm{s}} \\
\text { front spar } \quad[-30 / 30 /-30 / 30]_{\mathrm{s}} \\
\text { rear spar } \quad[30 /-30 / 30 /-30]_{\mathrm{s}}\end{array}$ & $\begin{aligned} \mathrm{EI} & =0.3123 \\
\mathrm{GJ} & =0.6135 \\
\mathrm{~K} & =0.0\end{aligned}$ & $\begin{array}{l}\mathrm{V}_{\mathrm{f}}=158.1 \\
\omega_{\mathrm{f}}=87.6\end{array}$ & $\begin{array}{l}V_{f}=159.7 \\
\omega_{f}=93.6\end{array}$ \\
\hline $\begin{array}{l}\text { case } 1 \\
\text { Symmetric } \\
\text { Lay-up } \\
\text { (approach 1) }\end{array}$ & $\begin{array}{l}\text { top skin } \quad[45 /-45 / 45 /-45]_{\mathrm{s}} \\
\text { bottom skin }[-45 / 45 /-45 / 45]_{\mathrm{s}} \\
\text { front spar } \quad[45 /-45 / 45 /-45]_{\mathrm{s}} \\
\text { rear spar } \quad[45 /-45 / 45 /-45]_{\mathrm{s}}\end{array}$ & $\begin{array}{c}\mathrm{EI}=0.1217 \\
\mathrm{GJ}=0.7766 \\
\mathrm{~K}=0.0\end{array}$ & $\begin{array}{l}\mathrm{V}_{\mathrm{f}}=182.2 \\
\omega_{\mathrm{f}}=94.8\end{array}$ & $\begin{aligned} V_{f} & =181.4 \\
\omega_{f} & =96.0\end{aligned}$ \\
\hline $\begin{array}{c}\text { case } 2 \\
\text { Asymmetric } \\
\text { Lay-up } \\
\text { (approach 1) }\end{array}$ & $\begin{array}{ll}\text { top skin } & {[33.5 /-44.3 / 33.5 /-44.3]_{\mathrm{s}}} \\
\text { bottom skin } & {[-35.6 / 39.8 /-35.6 / 39.8]_{\mathrm{s}}} \\
\text { front spar } & {[-30 / 30 /-30 / 30]_{\mathrm{s}}} \\
\text { rear spar } & {[30 /-30 / 30 /-30]_{\mathrm{s}}}\end{array}$ & $\begin{array}{l}\mathrm{EI}=0.1934 \\
\mathrm{GJ}=0.7058 \\
\mathrm{~K}=0.0700\end{array}$ & $\begin{array}{l}\mathrm{V}_{\mathrm{f}}=186.7 \\
\omega_{\mathrm{f}}=76.8\end{array}$ & $\begin{array}{l}V_{\mathrm{f}}=186.0 \\
\omega_{\mathrm{f}}=64.5\end{array}$ \\
\hline $\begin{array}{c}\text { case } 3 \\
\text { Asymmetric } \\
\text { Lay-up } \\
\text { (approach 1) }\end{array}$ & $\begin{array}{l}\text { top skin } \quad[39.3 /-48.4 / 39.3 /-48.4]_{\mathrm{S}} \\
\text { bottom skin }[-39.3 / 50.9 /-39.3 / 50.9]_{\mathrm{S}} \\
\text { front spar } \quad[-30 / 30 /-30 / 30]_{\mathrm{s}} \\
\text { rear spar } \quad[30 /-30 / 30 /-30]_{\mathrm{S}}\end{array}$ & $\begin{array}{l}\mathrm{EI}=0.1342 \\
\mathrm{GJ}=0.7234 \\
\mathrm{~K}=0.1056\end{array}$ & $\begin{array}{l}\mathrm{V}_{\mathrm{f}}=187.2 \\
\omega_{\mathrm{f}}=86.4\end{array}$ & $\begin{array}{l}V_{f}=189.0 \\
\omega_{f}=89.0\end{array}$ \\
\hline $\begin{array}{c}\text { case } 4.1 \\
\text { Asymmetric } \\
\text { Lay-up } \\
\text { (approach 2) }\end{array}$ & $\begin{array}{lc}\text { top skin } & {[38.9 /-52.5 / 38.9 /-52.5]_{\mathrm{s}}} \\
\text { bottom skin } & {[-38.2 / 53.6 /-38.2 / 53.6]_{\mathrm{S}}} \\
\text { front spar } & {[46.3 /-46.6 / 46.3 /-46.6]_{\mathrm{s}}} \\
\text { rear spar } & {[-42.1 / 44.2 /-42.1 / 44.2]_{\mathrm{S}}}\end{array}$ & $\begin{array}{l}\mathrm{EI}=0.1467 \\
\mathrm{GJ}=0.7163 \\
\mathrm{~K}=0.1322\end{array}$ & $\begin{array}{l}V_{f}=174.3 \\
\omega_{f}=59.4\end{array}$ & $\begin{array}{l}\mathrm{V}_{\mathrm{f}}=170.0 \\
\omega_{\mathrm{f}}=51.9\end{array}$ \\
\hline $\begin{array}{l}\text { case } 4.2 \\
\text { Asymmetric } \\
\text { Lay-up } \\
\text { (approach 2) }\end{array}$ & $\begin{array}{lr}\text { top skin } & {[40.6 /-51.4 / 40.6 /-51.4]_{\mathrm{S}}} \\
\text { bottom skin } & {[-41.1 / 52.1 /-41.1 / 52.1]_{\mathrm{S}}} \\
\text { front spar } & {[46.3 /-46.6 / 46.3 /-46.6]_{\mathrm{S}}} \\
\text { rear spar } & {[-42.1 / 44.2 /-42.1 / 44.2]_{\mathrm{S}}}\end{array}$ & $\begin{array}{l}\mathrm{EI}=0.1309 \\
\mathrm{GJ}=0.7415 \\
\mathrm{~K}=0.1015\end{array}$ & $\begin{array}{l}V_{f}=187.0 \\
\omega_{f}=63.8\end{array}$ & $\begin{array}{l}\mathrm{V}_{\mathrm{f}}=187.5 \\
\omega_{\mathrm{f}}=81.0\end{array}$ \\
\hline
\end{tabular}

Aeroelastic optimisation (case 4.2). In order to achieve a maximum flutter speed, the optimised stacking sequence from above case 4.1 was then taken as a new starting point for a direct solution of the aeroelastic optimisation problem using equation (7). Taking all 16 variables again, the optimised lay-up and flutter results were obtained as shown in Table 1 (see case 4.2 results). Compared with the results for case 2 where the same objective function and number of variables were used,

\subsection{Effect of stiffness properties on flutter speed}

Once the mass, inertia property and geometry dimension of the wing have been determined, the computing time in this indirect optimisation approach is significantly less as expected. Similar to the case 2, the stacking sequences of the front and rear spar remain unchanged because the flutter speed is much less sensitive to their lay-up than that of the skins. The flutter speed is further increased by 7.3 percent from that in case 4.1 as can be seen in Table 1. As the final result of this approach, the flutter speed is increased by 18 per cent from the initial design.

the flutter speed largely depends upon the bending, torsional and coupling rigidities, which in turn depend on the laminate lay-up of the wing box. In order to compare the effect of bending and torsional rigidities on flutter 
behaviour, flutter speeds were also computed for the composite wing box in symmetric layup with fibre angles varying from 0 to 90 degree. In such symmetric lay-up, the coupling rigidity $K$ remains zero and thus has no effect on the flutter speed. As shown in Figure 3, the results indicate that the flutter speed follows a trend similar to that of the change in the torsional rigidity $G J$ without significant effect from bending rigidity $E I$. When $G J$ reaches its maximum value, the flutter speed also reaches maximum with its value $V_{f}=182.2 \mathrm{~m} / \mathrm{s}$, which is almost triple the value of $V_{f}=63.2 \mathrm{~m} / \mathrm{s}$ at minimum $G J$.

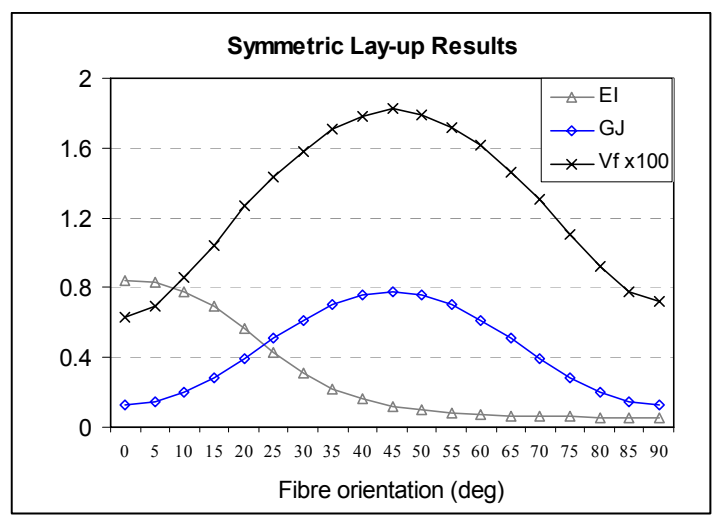

Figure 3. Rigidity $\left(\mathrm{MNm}^{2}\right)$ and flutter speed $(\mathrm{m} / \mathrm{s})$ variation as laminate plies change symmetrically at $\pm a$

Regarding the asymmetric lay-up cases, results in Table 1 shows that higher flutter speed can normally be achieved with the contribution of coupling rigidity. To investigate further the effect of torsional rigidity $G J$ and the coupling rigidity $K$, flutter speeds were also calculated for a number of asymmetric cases listed in Table 1 by taking $K=0$ and $G J=0.61 \mathrm{MNm}^{2}$ (initial lay-up). As shown in Figure 4, the flutter speeds are significantly reduced in all cases when coupling rigidity $K$ is ignored (i.e. taking $K=0)$. The flutter speeds are further reduced when the torsional rigidity $G J$ is reduced down to its initial lay-up value $\left(G J=0.61 \mathrm{MNm}^{2}\right)$.
Therefore more attention is worth paying to a desirable combination of $G J$ and $K$ for achieving a maximum flutter speed in asymmetric lay-ups.

During the investigation it has also been observed that lay-ups of some components of the box structure such as the front and rear walls (spars) have obvious effect on the rigidities. However they have little effect on the flutter speed of the wing box as shown in case 2 and 4.2. Therefore, attention is finally drawn to the effect of starting point for optimisation, selection of variables and approaches on the optimal lay-up result. In terms of flutter and optimisation efficiency, the second approach and the results in case 4.2 have the advantage over others.

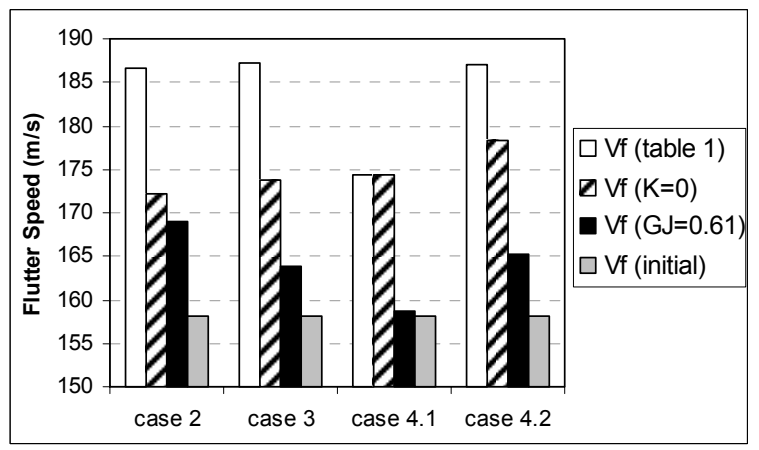

Figure 4. Effect of torsional and coupling rigidities on flutter speed

\subsection{Structure optimisation with aeroelastic constraint (stage 2)}

After the laminates lay-up tailoring in stage 1, it is noticed that the bending rigidity of optimised box beam has been significantly reduced, while the torsional rigidity has been increased in all cases. Consequently the ratio of maximum stress $\sigma(c)$ in the optimised laminates against the initial value $\sigma_{0}$ under the same loading condition is increased as shown

Table 2 Results of stage-2 optimisation

\begin{tabular}{|c|ccccccccc|c|c|c|}
\hline optimal & \multicolumn{7}{|c|}{ wing box width of each section (from root) } & stress & weight & flutter \\
stage & 1 & 2 & 3 & 4 & 5 & 6 & 7 & 8 & 9 & 10 & ratio $\mathrm{R}_{\mathrm{s}}$ & ratio $\mathrm{R}_{\mathrm{w}}$ \\
ratio $\mathrm{R}_{\mathrm{V}}$
\end{tabular}




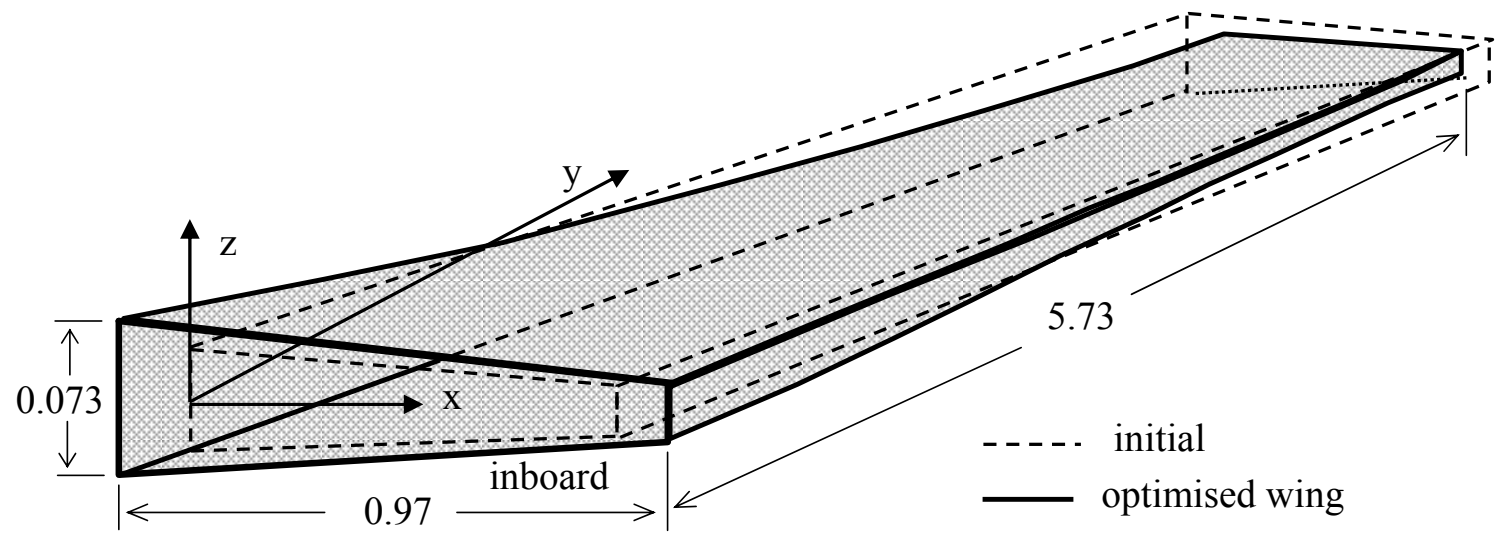

Figure 5. Optimized wing box configuration compared with the initial design

in the stage- 1 result of Table 2 . This raises the concern on the strength of the optimised wing structure. Therefore, in the 2nd stage of optimisation effort was made to minimise the strength reduction and weight of the wing box by carrying out the constrained optimisation described in section 3.3.

The solution shown for case 4.2 in Table 1 was chosen as the final aeroelastic tailoring result from stage-1. In the second stage, the constrained optimisation problem presented in equation (9) was solved. The wing structure was also divided into 10 beam elements (sections) spanwise to calculate the flutter speed and maximum stress in the laminates of each section. In the optimisation, the depth to width ratio of the sections in the spanwise direction was kept the same as the initial design so that only 10 design variables (wing box width) were involved. As the results shown in Table 2 and illustrated in Fig. 5 demonstrate, the wing box has been optimised from the initial uniform configuration to a tapered configuration. The change in stress ratio $R_{s}$ from 2.38 to 1.0 indicates that the maximum tensile stress in the laminates, which has been increased in stage 1 , has been reduced to the same level as the initial design. The change in weight ratio $R_{w}$ from 1.0 to 0.87 indicates that the total weight of the wing box has been reduced by 13 percent from its initial design. The unchanged flutter ratio $R_{v}$ indicates that the maximum flutter speed achieved in stage 1 has not been compromised in stage 2 constrained optimization.

\section{CONCLUSIONS}

A detailed investigation has been carried out on the aeroelastic optimisation and the effect of rigidities on flutter speed of a composite wing box. It has been demonstrated that by optimizing the fibre orientations a maximum flutter speed can be achieved without any weight penalty. This is a great advantage of laminated composite structure over its metallic counterpart in aeroelastic tailoring. Following conclusions may be drawn:

1. In comparison with the symmetric lay-up of a laminate wing box, the asymmetric lay-up is favoured for aeroelastic optimisation because of the contribution from bending-torsion coupling rigidity.

2. In comparison with the bending rigidity, both the torsional and the coupling rigidities have much more significant effect on the flutter speed of a composite wing. The torsional rigidity plays a relatively more dominant role in aeroelastic tailoring. No clear trend of the coupling rigidity effect on the flutter speed 
can be drawn from this investigation. A desirable combination of relatively large torsional and coupling rigidities would favour the flutter speed.

3. The solution of optimal lay-up is dependent on the initial lay-up, design variables and optimisation approach and thus is not unique.

4. The lay-ups of some structural components may have significant effect on the structural rigidities, but may have little effect on flutter behaviour. A careful selection of initial lay-up and/or design variables may improve the optimisation efficiency.

5. An unconstrained aeroelastic optimization for maximum flutter speed might reduce the laminate strength of a composite wing structure. The strength set in the initial design can be regained without compromising the maximum flutter speed and the weight by optimizing the wing structure in a constrained optimization.

\section{REFERENCES}

1. Weisshaar, T. A. Divergence of SweptForward Composite Wings, Journal of Aircraft, Vol 17, No. 6, 1980, pp442-448

2. Librescu, L. and Khdeir, A.A. Aeroelastic Divergence of Swept-Forward Composite Wings Including Warping Restraint Effect, AIAA Journal, Vol, 26, No.11 Nov. 1988, pp1373-1377

3. Librescu, L. and Simovich, J. General Formulation for the Aeroelastic Divergence of Composite Swept-Forward Wing Structures, Journal of Aircraft, Vol 25, No. 4, 1988, pp364371

4. Librescu, L. and Thangjitham, S. Analytical Study on Static Aeroelastic Behavior of SweptForward Composite Wing Structures, Journal of Aircraft, Vol 28, No. 2, 1991, pp151-157

5. Hollowell, S. J. and Dugundji, J. Aeroelastic flutter and divergence of stiffness coupled graphite/epoxy cantilevered plates, Journal of Aircraft, Vol. 21, No.1, Jan. 1984, pp.69-76.

6. Lottati, I. Flutter and divergence aeroelastic characteristics for composite forward swept cantilever wing, Journal of Aircraft, Vol. 22, No.11, Nov. 1985, pp.1001-1007.
7. Guo, S., Cheung, C.W., Banerjee, J.R. and Butler, R. Gust alleviation and flutter suppression of an optimised composite wing, Proceedings of the International Forum on Aeroelastisity and Structural Dynamics, Manchester, U.K. June 1995, pp.41.1-41.9

8. Lillico, M., Butler, R., Banerjee, J.R. and Guo, $\mathrm{S}$. Optimum design of high aspect ratio wings subject to aeroelastic constraints, Proceedings of the 36th AIAA/SME/ASEC/AHS/ASC Structures, Structural Dynamics and Materials Conference, April 1995, pp.558-566

9. Georghiades, G.A., Guo, S. and Banerjee, J.R. Flutter Characteristics of Laminated Wings, Journal of Aircraft, Vol.33, No. 6, 1996, pp. 1204-1206

10. Lillico, M., Butler, R., Guo, S. and Banerjee, J.R. Aeroelastic optimisation of composite wings using the dynamic stiffness method, The Aeronautical Journal, Vol. 101, No. 1002, February 1997, pp.77-86

11. Hong, C.H. and Chopra, I. Aeroelastic stability analysis of a composite rotor blade, Journal of the American Helicopter Society, April 1995, pp.57-67.

12. Rehfield, L.W., Atilgan, A.R. and Hodges, D.H. Nonclassical behaviour of thin-walled composite beams with closed cross section, Journal of the American Helicopter Society, May 1990, pp.42-50.

13. Hodges, D.H., Atilgan, A.R., Fulton, M.V. and Rehfield, L.W. Free vibration analysis of composite beams, Journal of the American Helicopter Society, July 1991, pp. 36-47

14. Berdichevsky, V., Armanios, E.A. and Badir, A.M. Theory of anisotropic thin-walled closed cross-section beams, Journal of Composite Engineering, Vol.2, No. 5-7, 1992, pp.411-432.

15. Armanios, E.A. and Badir, A.M. Free vibration analysis of anisotropic thin-walled closed-cross-section beams, Paper No. AIAA94-1327-CP, July 1994, pp.164-171.

16. Banerjee, J.R. and Williams, F.W. Coupled bending-torsional dynamic stiffness matrix for Timoshenko beam elements, Computers \& Structures, Vol.42, 1992, pp.301-310

17. Banerjee, J.R. and Williams, F.W. Free vibration of composite beams - an exact method using symbolic computation, Journal of Aircraft, 1995, 32, (3), pp.636-642

18. Wittrick, W.H. and Williams, F.W. A general algorithm for computing natural frequencies of elastic structures, Quarterly Journal of Mechanics and Applied Mathematics, Vol.24, 1971, pp.263-284 
19. Davies, D.E. Theoretical determination of subsonic oscillatory airforce coefficients, ARC $\mathrm{R}$ and M 3804, May 1976

20. Matthews, F.L. and Rawlings, R.D. Composite Materials: Engineering and Science, Chapman \& Hall, 1994
21. Fletcher, R. and Powell, M. J. D. A rapidly convergent method for minimisation, Computer Journal, Vol. 6, No.2, 1963, pp.163-168

22. Fox, R.L. Optimisation Methods for Engineering Design, 1971 Addison-Wesley, Reading Massachusetts. 